\title{
A arqueologia como paradigma de ciência histórica e interdisciplinar
}

\author{
Astolfo Gomes de MELLO ARAUJO ${ }^{I}$
}

\begin{abstract}
Considerando o quão semelhante a biologia evolutiva é da ciência histórica e o quão diferente ela é da física [...] não é surpreendente que estipular uma linha definida entre as ciências naturais e as humanidades seja tão difícil, na verdade quase impossível. (Mayr, 2004, p.13)
\end{abstract}

U

M LONGO e amplo debate tem sido travado entre filósofos da ciência a respeito do que é ciência (Mahner; Bunge, 1997; Mayr, 1982). Tal debate passa ao largo do interesse da maioria dos praticantes de ciência, e a impressão que se tem é a de que as pessoas (e não me refiro apenas ao público leigo) imaginam que ciência seja uma atividade facilmente definida e definível, algo ligado a análises laboratoriais, experiências controladas e testes formais de hipóteses, utilizando-se do famigerado método científico, tudo isso regido por leis. Creio que seja essa a visão por trás de afirmações pouco informadas do tipo “Arqueologia não é ciência porque não se pode testar hipóteses” ou "Arqueologia não é ciência porque o comportamento humano não é regido por leis".

Até os anos 1970, a filosofia da ciência era dominada por físicos (Mayr, 1982; Sterelny, 2009; Wylie, 2002) e, portanto, é fácil entender porque a física era considerada o modelo de ciência a partir do qual as outras disciplinas seriam avaliadas.

Como a Física é uma disciplina experimental, fortemente apoiada em leis, e passível de ter suas hipóteses testadas de maneira formal, qualquer disciplina que não apresentasse essas características seria considerada automaticamente uma não ciência ou, na melhor das hipóteses, uma quase-ciência. Os modelos de descoberta científica eram a mecânica newtoniana ou as leis de Kepler, que permitem generalizações a partir de observações empíricas, além de predições. A partir do fim dos anos 1960, porém, esse modelo empiricista começou a ser atacado por pensadores como Karl Popper, Imré Lakatos, Thomas Kuhn e Paul Feyerabend, mas os exemplos continuavam a provir da Física (Sterelny, 2009, p.325). Kuhn (1970) e Feyerabend (2009) propuseram uma visão do conhecimento científico que não era cumulativa, mas descontínua; um corpo teórico seria normalmente suplantado por outro quando não conseguisse mais dar conta dos fenômenos a serem explicados. Isso pode realmente ser verdade na física, mas está longe de ser 
geral, e absolutamente não aconteceu na biologia, por exemplo (Godfrey-Smith, 2003; Sterelny, 2009). Daí o problema de se tomar a filosofia da ciência como algo prescritivo (Clarke, 1972; Dunnell, 1982). Em suma, não se pode esquecer de que não é papel da filosofia da ciência estipular o modo como as ciências deveriam ser, mas tentar explicar como elas funcionam. Logo começaram a aparecer problemas no modelo de "ciência-enquanto-física", e o principal deles é que outros ramos respeitáveis do conhecimento não se encaixavam no modelo de ciência - por exemplo, a geologia e a biologia. Foi no âmbito da biologia que as críticas ao modelo de "ciência-enquanto-física" foram mais abundantes, gerando pelo lado dos biólogos frases como "a arrogância dos físicos", e pelo lado dos físicos afirmações como "a biologia não passa de uma coleção de selos" (exemplos em Mayr, 1982, p.33). O debate chegou ao auge quando o influente filósofo (e físico) Karl Popper (1974) afirmou que o darwinismo era um "programa metafísico", e não uma ciência, por não conter leis universais, não conseguir predizer o curso da evolução, e não ser testável, o que gerou reação por parte de biólogos e filósofos, como Hull (1999), Lewontin (1972), Ruse (1977) e Wasserman (1981). Vários aspectos das críticas levantadas por Popper foram debatidos, entre eles a questão de que o darwinismo seria tautológico (Hull, 1999), e ficou claro que Popper não tinha um conhecimento tão profundo sobre a teoria da evolução (ver também Fabian 2009). Seja como for, esse debate foi bastante importante porque, como notou Hull (1999), é incomum que cientistas sejam influenciados por filósofos. O debate mostrou a necessidade de se pensar qual o status científico das disciplinas que não se encaixam no estereótipo da física.

\section{Tipos de ciência}

Uma primeira divisão que pode ser feita em termos de tipos de ciência é entre ciências formais e ciências factuais (Mahner; Bunge, 1997; Bunge, 1998). As ciências formais lidam com ideias, somente. Exemplos são a lógica e a matemática. Elas não dependem de evidências provenientes do mundo material para validação de suas fórmulas e postulados. As ciências factuais, por outro lado, são as que lidam com fenômenos, com o mundo material, construindo dados a partir dos fenômenos e sendo sempre confrontadas com sua capacidade de explicar esse mundo material. Exemplos de ciências factuais são os mais abundantes, da física à psicologia. Ainda assim, as ciências factuais são bastante distintas entre si, e aqui entra uma outra categorização, que é a divisão entre ciências históricas e ciências ahistóricas (também chamadas de ciências experimentais; ver Cleland, 2001; Frodeman, 1995; Hull, 1975).

Segundo Mayr (2002), foi Darwin quem introduziu a perspectiva científica histórica, mas podemos recuar até Descartes que, ao contrário de Newton, jogava com a possibilidade de a Terra ter uma História, ou seja, não ter sido criada por Deus do jeito que hoje se nos apresenta (Rossi, 1992, p.70-5). Por outro lado, a visão de mundo de Newton era a-histórica, porque havia leis físicas que regulavam o universo, mas o universo teria sido criado por Deus, que teria colo- 
cado todos os planetas e estrelas em seus devidos lugares, e só depois operado o início das leis físicas. Especular sobre as origens do universo, para Newton, seria uma atitude sem sentido (Rossi, 1992, p.67). Assim, a física já nasce a-histórica.

A diferença entre os dois tipos de ciência é fundamental, uma vez que são baseadas em ontologias radicalmente diferentes (Dunnell, 1982). As ciências a-históricas, exemplificadas por física, química e demais ciências experimentais, são baseadas em uma ontologia eminentemente essencialista (pensamento tipológico), ao passo que as ciências históricas são baseadas em uma ontologia materialista (pensamento populacional - Mayr, 1972; Sober, 1980). Enquanto as ciências a-históricas respondem a perguntas do tipo "como?", as ciências históricas respondem perguntas do tipo "por quê?" (Mayr, 1961). As ciências a-históricas se preocupam com o funcionamento de sistemas ou fenômenos ("como isso funciona?"), enquanto as ciências históricas têm interesse em por que os sistemas funcionam do jeito que funcionam ("por que isso é assim?"). Outra distinção possível (Mayr, 1961) é que as ciências a-históricas se ocupam de causas próximas (proximate causation), enquanto as ciências históricas se ocupam de causas fundamentais (ultimate causation). Um exemplo de causa próxima seria entender o sistema circulatório dos mamíferos como operado pelo coração em conjunto com os pulmões, veias e artérias. Nesse sentido, o estudo do sistema circulatório se interessa em como ele funciona, entendendo a bioquímica e o papel desempenhado por esses diferentes órgãos. Trata-se, assim, de uma pergunta eminentemente funcional. Por outro lado, as causas fundamentais da existência do sistema circulatório dos mamíferos, ou por que ele se diferencia dos sistemas circulatórios de outras classes de animais e plantas, se relaciona a adaptações ocorridas ao longo de centenas de milhões de anos. É uma pergunta eminentemente histórica.

A ontologia condiciona os tipos de perguntas que são feitas, e também a natureza do próprio conhecimento científico, ou seja, sua epistemologia. Uma disciplina que enxerga o mundo como constituído por tipos reais e definidos, cujas características internas são objeto de interesse e estudo, e que enxerga a variação como "ruído"; que se interessa no modo como os fenômenos se articulam dentro de uma perspectiva funcional; que se interessa nas causas imediatas que afetam os fenômenos, e de como os fenômenos respondem a estímulos imediatos, vai fazer perguntas do tipo "como isso funciona"?

Por outro lado, uma disciplina que enxerga os tipos como meras abstrações, agregados de casos individuais; que atenta para a variação entre tipos, considerando-a o objeto de explanação; que monitora e se interessa pelas mudanças dessa variação ao longo do tempo e que busca as causas fundamentais que moldaram essa variação, vai fazer perguntas do tipo "por que isso é assim"?

Além de todas essas características contrastantes há, por fim, uma diferença que está no cerne da impossibilidade de se encaixar as ciências históricas dentro do modelo da física: o alto grau de contingência e imprevisibilidade que o processo histórico traz em si. Ao contrário da visão "clássica" de ciência, 
de que "explanação é predição", nas ciências históricas há uma independência entre explanação e predição (Frodeman, 1995). Pode-se explanar um processo evolutivo, mas não se pode predizer qual será seu resultado. Há vários motivos que estão na base da indeterminação das ciências históricas (Mayr, 1961; 1996): a aleatoriedade dos eventos em relação à sua significância; a especificidade de todas as entidades que estejam em níveis de complexidade superiores ao das moléculas; a emergência de novidades qualitativas, quando os indivíduos se agregam e formam organizações; o importante papel explanatório das narrativas históricas; a alta frequência de processos estocásticos e, por fim, a interação de múltiplas causas. Tudo isso faz que nas ciências históricas as "leis", generalizações e capacidade preditiva tenham um papel extremamente secundário, ou mesmo inexistente (Scriven, 1959).

Fica claro, portanto, que existem duas maneiras tão distintas de se encarar o mundo do ponto de vista científico, que as diferenças entre as disciplinas como as conhecemos hoje poderiam ser reinterpretadas à luz dessas ontologias sem nenhum prejuízo de julgamento: ao invés de separarmos as disciplinas por seu objeto de estudo (disciplinas que estudam "os planetas" ou "os seres vivos" ou "o Homem"), poderíamos separá-las do ponto de vista ontológico; poderíamos perfeitamente dividi-las entre disciplinas históricas e a-históricas: assim, parte do que conhecemos por "Biologia" é a-histórica (ecologia, biologia molecular) e outra parte é histórica (biologia evolutiva, paleontologia). No caso da astronomia, parte seria a-histórica, mas teríamos também a cosmologia, que lida com eventos históricos na formação do universo (a ponto de se estar agora falando em "Arqueologia Galática"; ver Stello et al., 2015). A geologia tem um componente a-histórico relacionado, por exemplo, à mineralogia e petrografia (dadas condições de temperatura $\mathrm{X}$ e pressão $\mathrm{Y}$, e dada a composição original do magma, sabe-se exatamente quais minerais irão se formar), mas de maneira geral é uma disciplina eminentemente histórica. No caso das Humanidades, teríamos a sociologia, a economia, a antropologia e a geografia humana como a-históricas, e a arqueologia, a geografia física (geomorfologia, pedologia) e obviamente a história como ciências históricas. $\mathrm{O}$ fato de as disciplinas acadêmicas atuais serem divididas em tópicos é apenas fruto de sua... história.

Em suma, podemos definir ciência como:

Ciência é um sistema de conhecimento que visa fornecer explanações a respeito de fenômenos por meio de um encadeamento retroalimentador de ideias, protocolos e atividades.

O que entendemos por "sistema de conhecimento" é um conjunto de ideias que visa dar significado a algo. Há vários outros sistemas possíveis, como o senso c0omum e a religião, sem contarmos os sistemas cosmológicos empregados por outras sociedades, como colocado por Willer e Willer (1973). O encadeamento de ideias, protocolos e atividades a que se refere a definição acima são normalmente conhecidos pelos termos "teoria", "método" e "técnica". 


\section{O método científico nas ciências experimentais e nas ciências históricas}

Tendo em vista a discussão anterior sobre a existência de modalidades ontologicamente distintas de ciência, o que podemos dizer a respeito do chamado "método científico"? Existiria um "método científico" no singular? Obviamente não, apesar de tal ideia ser predominante no senso comum, dentro e fora da academia. Essa ideia genérica coloca "O" método científico como sendo algo relacionado à execução de experimentos em laboratório e teste de hipóteses, por algumas vias (ou mesmo uma combinação de várias): a indução científica, o método hipotético-dedutivo ou o falsificacionismo (Cleland, 2001, p.987; Wylie, 2002, p.4). A indução científica, método que remonta a Francis Bacon, diz que se tivermos uma hipótese $\mathrm{H}$ que prevê a manifestação de um evento $\mathrm{Z}$ sob condições $X$, e realmente observarmos o evento $Z$ toda vez que as condições $\mathrm{X}$ estão operantes, então podemos dizer que existem evidências confirmando a verdade dessa hipótese $\mathrm{H}$. O método hipotético-dedutivo de Hempel envolvia o estabelecimento de regularidades na forma de leis, e o teste de uma hipótese se faria confirmando que um evento $\mathrm{Z}$ ocorre quando condições $\mathrm{X}$ se verificam, sendo que existe uma lei que prevê essa relação (Gibbon, 1989). Porém, tanto o indutivismo como o dedutivismo sofrem de um problema básico, que é o fato de que para se provar que uma hipótese é verdadeira teríamos que testá-la infinitamente. Nenhum corpo finito de evidências é suficiente para provar uma hipótese. A saída encontrada foi dada pelo falsificacionismo (Dutra, 2009, p.51) que se vale do "modus tollens", uma regra de inferência lógica que diz que uma generalização é falsa se houver ao menos uma instância em que ela não se verifica, ou seja, não é possível provar que uma hipótese é verdadeira, mas é possível provar que ela é falsa.

Até aqui tudo parece muito simples, e uma dessas versões do "método científico" costuma ser invocada em livros e artigos dirigidos a um público que vai do ensino básico às universidades, mas se vimos que o indutivismo é logicamente falho, há também alguns problemas básicos com o falsificacionismo (Cleland, 2001; O’Meara, 1989):

1) Na vida real, todo teste de hipóteses envolve um grande número de pressupostos auxiliares. Quando um ou mais desses pressupostos não se verifica, não há como saber se a falha em observar o resultado previsto é real ou não, ou seja, se ela se relaciona ao evento sendo testado, ou a um problema com os pressupostos auxiliares.

2) Conforme colocado por Kuhn (1970, p.77), os cientistas quase nunca praticam o falsificacionismo. Na ocorrência de um teste que aponta para uma falha da hipótese, o procedimento rotineiro é tentar achar alguma falha nos procedimentos ou nos equipamentos, antes de sair publicando artigos alardeando a falsificação da hipótese.

3) Há um problema lógico com o falsificacionismo. Uma "instância nega- 
tiva" só pode existir em contraposição a algo que seria considerado uma "instância positiva”, mas essa não pode ser logicamente produzida (O’Meara, 1989, p.358).

Segundo Cleland (2001, p.988) a tentativa de se "salvar" uma hipótese invocando a falha em um pressuposto auxiliar é logicamente aceitável e até recomendável. Na realidade, os cientistas experimentais não se comportam como bons falsificacionistas, mas tentam detectar e neutralizar falsos positivos e falsos negativos.

No caso das ciências históricas, o método científico não é estritamente falsificacionista, tendo em vista a impossibilidade de se realizar experimentos controlados em laboratório, mas isso não quer dizer que as hipóteses não possam ser avaliadas. O que geralmente ocorre nas ciências históricas é a avaliação de múltiplas hipóteses (Chamberlin, 1897; Gilbert, 1886), com a checagem dos dados em campo ou laboratório, que podem resultar no descarte de hipóteses que não se mostram adequadas para explicar os fenômenos observados. Na prática, porém, a ênfase é na busca de evidências positivas, e não de evidências que levem ao falseamento de hipóteses (Cleland 2002, p.483).

Frodeman (1995) apresenta uma argumentação de que a abordagem científica nas ciências históricas (especialmente na geologia) se daria a partir do método hermenêutico. A hermenêutica, que pode ser entendida como "interpretação", foi originalmente desenvolvida no final do século XVIII em um contexto teológico, ou seja, era uma atividade voltada para a interpretação de textos bíblicos. Posteriormente, filósofos alemães como Dilthey, Heidegger e Gadamer desenvolveram o método hermenêutico como uma maneira de se compreender a linguagem falada e escrita (Schmidt, 2014). Um dos conceitos centrais da hermenêutica é o de círculo hermenêutico, que entende a interpretação como sendo um raciocínio de mão dupla, onde o entendimento do todo depende do entendimento das partes, e vice-versa. $\mathrm{O}$ entendimento de uma formação geológica, por exemplo, depende do entendimento de afloramentos de rocha individuais. Por outro lado, esses afloramentos individuais só podem ser entendidos de maneira satisfatória após o entendimento da formação geológica como um todo (Frodeman, 1995, p.963). Fica claro que esse conceito de "ler" um "texto", de círculo hermenêutico, ou de pensamento circular, não se coaduna com a ideia de objetividade do positivismo. No entanto, funciona perfeitamente para disciplinas onde há uma grande profundidade temporal e a implicação de uma multiplicidade enorme de fatores em jogo. É importante frisar que há diferentes posturas ontológicas dentro do que se chama genericamente de hermenêutica, sendo algumas mais relativistas e outras mais propensas a aceitar que possa existir uma aproximação com o significado original de um "texto" (em sentido literal ou figurado), chegando-se a uma compreensão correta do mesmo. Até fins dos anos 1990 a maioria dos filósofos considerava que a hermenêutica não tinha qualquer papel nas ciências naturais e, na verdade, serviria como um critério de 
separação entre os domínios social e natural (Eger, 1997). Essa postura mudou bastante desde então, e a ideia de se usar a hermenêutica para entender como funciona a ciência em geral, e não apenas as Humanidades, tem ganhado cada vez mais fôlego (e.g., Babich; Ginev, 2014; Crease, 1997; Heelan, 1997, 1998; Mantzavinos, 2005).

Em suma, se o indutivismo é logicamente falho e o falsificacionismo não é efetivamente aplicado, não há como se justificar uma suposta superioridade epistemológica das ciências experimentais em relação às ciências históricas. Trata-se simplesmente de duas maneiras que nossa sociedade se utiliza para lidar com a extrema complexidade do Universo. Assim, cai por terra a ideia de uma teoria científica unificada, que supõe que todo o conhecimento deva ser, em ultima instância, desenvolvido nos moldes da física e da química e que, portanto, as ciências históricas são, no fundo, um tipo de ciência pouco desenvolvida (Frodeman, 1995). Isso ocorre porque o Universo é repleto de instâncias onde se manifestam as chamadas propriedades emergentes, ou seja, propriedades que resultam da interação de diferentes componentes, produzindo algo que não pode ser entendido como apenas a soma dos mesmos (Simpson, 1963, p.38).

\section{Arqueologia como ciência}

A propensão em conceber a arqueologia enquanto ciência não é recente. Esforços programáticos colocando a necessidade de a arqueologia ser baseada em observações empíricas e não em mera especulação foram feitas desde pelo menos meados do século XIX nos Estados Unidos (Dunnell, 1992, p.77-8).

No início dos anos 1960 arqueólogos norte-americanos fundaram a "New Archaeology" ou Processualismo, uma reação à História Cultural, paradigma dominante na arqueologia anglo-saxã. A História Cultural foi muito bem-sucedida ao apresentar esquemas cronológicos, ou crônicas, onde diferentes "culturas" arqueológicas se desenvolviam no tempo e no espaço, mas seu poder explanatório foi sendo considerado cada vez menos satisfatório. O Processualismo pode ser definido, de maneira sintética, como uma reação à História Cultural, uma tentativa de tornar a disciplina mais científica e menos historicizante (Binford, 1962). O único acidente de percurso foi o fato de que o modelo de ciência escolhido era totalmente inadequado, um modelo de "ciência-enquanto-física". Usou-se o modelo nomológico-dedutivo de Hempel, o chamado Empiricismo Lógico ou Positivismo Lógico, que teve suas raízes no chamado "Círculo de Viena", nos anos 1920 e 1930 (Embree, 1992), como o padrão aceitável de ciência (e.g., Bamforth; Spaulding, 1982; Binford, 1968). Os principais pressupostos desse programa eram a necessidade de se utilizar uma abordagem hipotético-dedutiva (ou seja, a explanação se daria por meio do teste de hipóteses); a busca de leis gerais (Fritz; Plog, 1970); e a crença em uma unidade essencial do método científico (Gibbon, 1984, p.13). As críticas a esse programa foram se acumulando ao longo do tempo (e.g., Bayard, 1969; Dunnell, 1984; Johnson Jr., 1972; Klejn, 2001), inclusive porque para os filósofos da ciência o modelo 
de Hempel era falho e já estava datado (Gibbon, 1989), e a ideia de que só existia um modelo de ciência possível estava sob forte ataque.

De modo relativamente paralelo, na Europa Ocidental, a voz mais ativa em termos de colocar a arqueologia como uma empreitada científica foi David Clarke $(1968,1973)$. A proposta de Clarke diferia em vários pontos da proposta de Binford, sendo um tanto menos "antropológica" em termos teóricos e valendo-se basicamente da Teoria dos Sistemas como arcabouço para lidar com o conceito de cultura. Por outro lado, em comum com Binford, Clarke enfatizou bastante a necessidade de se colocar os conceitos de maneira explícita e de se utilizar métodos quantitativos para balizar inferências, além de se utilizar de conceitos advindos da Ecologia Cultural. O ponto fraco do trabalho de Clarke, e que converge com o Processualismo, se refere aos problemas inerentes de se utilizar duas abordagens eminentemente sincrônicas (Teoria dos Sistemas e Ecologia) para se lidar com mudança diacrônica.

\section{Ações e reações}

Os fatores apresentados acima levaram a arqueologia a um beco sem saída, gerando uma insatisfação crescente e uma resposta com fundamentação anticientífica, derivada da ideia de pós-modernidade (Lyotard, 1984), que foi chamada de "Pós-processualismo" por falta de termo melhor (e.g., Shanks e Tilley, 1987). Podemos dizer que o termo Pós-processualismo abrange quase tudo o que veio em termos de crítica ao Processualismo e, portanto, não faz jus à pluralidade de abordagens (Kohl, 1997). Por outro lado, há uma linha mestra que está presente em quase todas as abordagens pós-processualistas, e esta é a postura anticientífica (Dunnell, 1992). Ou seja, o termo Pós-processualismo é útil para descrever o anticientificismo de maneira geral, apesar de o anticientificismo não ser restrito apenas ao Pós-processualismo. O tom de ironia nessa fase da história da arqueologia é que os arqueólogos pós-processualistas usaram, contra os processualistas, os mesmos truques retóricos que estes últimos usaram contra os histórico-culturalistas que os precederam: a propagação da ideia de que existia um hiato teórico abissal e intransponível, e que a partir daquele momento tudo seria novo e diferente, com uma ruptura de paradigma sem precedentes (e. g. Tilley, 1994, p.67).

Tomando carona na onda pós-processualista temos, hoje, em alguns rincões da arqueologia, profissionais com tamanha aversão a tudo o que possa ser científico que chegam às raias do histrionismo. Fala-se em "ciência desumanizadora", por exemplo, como se entender a humanidade tivesse que ser sempre feito por meio de algum tipo de ato de fé humanista. Apesar de isso tudo vir embrulhado em jargão (pós) moderno, trata-se da mesma velha reação dos pensadores românticos alemães frente ao Iluminismo, que volta sempre, como um morto-vivo. Kulturversus Civilization (Kuper, 1999, p.6). Fala-se em "colocar mais poesia" na arqueologia. Fala-se em "sentir" os materiais e "vivenciar" os sítios arqueológicos. Tenta-se uma linguagem literária para contrapor os "ári- 
dos" artigos científicos. O resultado acaba sendo nenhuma ciência acoplada a má literatura. (Nem todo mundo pode ser Stephen Jay Gould.)

Temos, então, uma situação interessante na história recente da arqueologia, onde o pouco conhecimento acerca do que é ciência por parte de seus praticantes resultou em duas correntes antagônicas: uma delas empreendeu a busca de ideais científicos por meios inadequados, enquanto a outra rejeitou em bloco o que era (erroneamente) considerado como ciência. Essa ignorância básica é facilmente percebida quando alguém, arqueólogo ou não, argumenta que a arqueologia não é uma ciência porque "o comportamento humano não obedece a leis", ou porque "não se pode replicar aspectos da história da humanidade em laboratório". Conforme vimos, estas noções são descabidas e, no entanto, comuns. Nessa visão, ciência é algo para ser aplicado apenas a plantas, animais irracionais e objetos inanimados, ou seja, aos "outros", seguindo uma linha de pensamento que pode ser exemplificada por Wilhem Dilthey (1833-1911), ao argumentar que as Humanidades podem apenas compreender, e nunca explicar, porque o distanciamento permitido ao cientista natural é impossível ao estudioso da sociedade: "A Natureza é estranha a nós. É um mero exterior a nós sem vida interna. A sociedade é o nosso mundo" (Dilthey, 1989, p.88). O resultado dessa visão clássica pode ser observado em um livro-texto intitulado "O que é Teoria", onde o autor escreve: "A formulação da teoria nas ciências humanas tem que ser mais aberta, visto que seu objeto de investigação não é o mero dado bruto da natureza [...]" (Pereira, 1990, p.58).

Ora, não pode existir algo como "observação de meros dados brutos da natureza". Todas as disciplinas, por mais "inumanas" que sejam, só conseguem produzir dados por meio de teoria que, como se sabe, condiciona as observações, as descrições e, portanto, a construção dos dados.

Um exemplo claro é o conceito de espécie. Para alguém pouco afeito à biologia, uma espécie seria um "dado bruto da natureza", uma vez que é muito fácil perceber as diferenças entre um cão, um gato e um repolho. Na realidade, o conceito de "espécie" gera mais discussão na Biologia do que o conceito de "agência" na arqueologia (De Queiroz, 2007).

Não só a teoria, mas até mesmo questões mais mundanas como o simples ato de descrever entram nessa postura hamletiana de "tudo é muito difícil e complexo". Por exemplo, o antropólogo Phillipe Descola (2005, p.68) coloca o seguinte ponto:

Pareceria que a descrição não requer descrição: por falta de instrumentos de medida apropriados, os etnógrafos só precisam estar atentos e curiosos a respeito de tudo; [...]. Porém, em uma ciência onde o observador e o observado compartilham propriedades em comum, a descrição nunca é tão simples.

Imaginar que a construção teórica na Física ou na Biologia, ou as observações na Geologia sejam mais "fáceis" ou passíveis de maior rigor porque essas 
disciplinas têm apenas que "olhar para os dados brutos da natureza" é ignorar a distinção básica entre fenômenos e dados. Fenômenos são percepções acerca de algo que "existe lá fora" (ou seja, fatos) feitas por um ser senciente. Dados são proposições a respeito de um determinado fato, realizada por meio da observação e registro sistemático de fenômenos. Se fossemos usar esse tipo de "argumento da dificuldade inerente", as construções teóricas nas ciências históricas deveriam ser consideradas ainda mais difíceis, porque além de não se valerem de nenhum tipo de linguagem comum entre o pesquisador e o objeto de estudo, envolvem escalas de tempo incomensuráveis. Um exemplo dessa argumentação foi colocado por Robert Frodeman (1995, p.965), filósofo e geólogo:

[...] historiadores da cultura humana têm exemplos modernos de revolução ou histeria em massa para examinar e comparar com os registros do passado. Mas a geologia [...] é histórica em um sentido mais profundo; dada a complexidade dos eventos geológicos, nossa falta de experiência em todos os ambientes geológicos e em intervalos de tempo geológicos, e nosso interesse na singularidade de cada evento, geólogos não podem simplesmente projetar o presente no passado.

Descola nos diz que a mera descrição nas Humanidades já é uma tarefa complexa porque o observador e observado compartilham propriedades comuns. Por outro lado, Frodeman diz exatamente o contrário; por nãa compartilharem nada em comum com o tempo presente, os eventos geológicos são de uma complexidade extrema.

No caso da arqueologia, obviamente diferentes perspectivas pessoais vão redundar em diferentes respostas a respeito do status científico da disciplina. Os argumentos construídos ao longo deste texto apontam para a possibilidade (e, por uma questão ética, para a necessidade) de uma abordagem científica em arqueologia. Resta esclarecer a que tipo de ciência nos referimos, e um bom começo é dissecar a divisão entre "ciência" e "história", ou entre "nomotético" e "idiográfico", e que tem sido um dos principais entraves no entendimento do tipo de ciência que pode ser a arqueologia.

\section{"Ciência" versus "História"}

O caráter nomotético ou idiográfico das Humanidades foi considerado determinante em termos do estabelecimento de uma postura científica. O debate entre Leslie White e Alfred Kroeber é bastante ilustrativo porque ambos foram figuras proeminentes na antropologia e, por consequência, na arqueologia.

Basicamente temos a posição de Kroeber entendendo a característica distintiva da abordagem histórica, em qualquer campo de conhecimento, como sendo não apenas a lida com sequencias cronológicas, mas um esforço para uma "integração descritiva" (Kroeber, 1935, p.545). Por descrição, Kroeber entendia que os fenômenos observados deveriam ser preservados intactos, e não decompostos em seus elementos constituintes, como pediria uma abordagem a-histórica. Kroeber continua seu raciocínio e aponta para o uso bem-sucedido 
da abordagem histórica em outras disciplinas, como a Geologia e a Biologia. Para Kroeber a evolução era uma empreitada histórica, assim como a Antropologia deveria ser. Suas críticas ao funcionalismo eminentemente a-histórico de Radcliffe-Brown e Malinowsky vão nessa direção (Kroeber, 1935, p.559). Ainda assim, Kroeber (1935, p.569) diferenciava "ciência" de "história". O que Kroeber propunha era o uso complementar de ambas as abordagens, uma científica e outra não científica, na antropologia.

A posição de White era bastante diferente. Para ele, havia uma diferença fundamental entre evolução e história. História seria "uma sequencia temporal de eventos únicos", enquanto evolução seria "uma sequencia temporal de formas" (White, 1946, p.82). Evolução, para White, lidaria com classes de fenômenos, e não com os fenômenos em si. A história dos cavalos ou da escrita seria diferente da evolução dos cavalos ou da escrita. A primeira lidaria com fenômenos, com eventos únicos, ligados a um espaço e tempo específicos, enquanto a segunda lidaria com classes de fenômenos, sem se preocupar com espaços ou tempos específicos. Uma é particularizante, a outra generalizante etc. White acreditava que a "confusão" entre história e evolução perpetuada por Kroeber (e Boas) era uma manobra para fazer o processo evolutivo "desaparecer". O que não fica claro no raciocínio de White é como alguém pode escrever a historia dos cavalos (para usar a analogia biológica que ele mesmo fez) enquanto algo único, se a história dos cavalos só pode ser feita em cima de uma população de cavalos, ou seja, de uma classe de mamíferos ao longo do tempo, e não de um cavalo único; e ao mesmo tempo, como a evolução dos cavalos pode ser entendida como dissociada de um tempo e espaço específicos, já que não havia cavalos no Devoniano, e nem os há na Antártida?

A impressão que temos é a de que White e Kroeber não estavam falando sobre a mesma coisa. White concedia que tanto a história como o evolucionismo tinham um componente temporal, mas não entendia como Boas (1904, p.515) poderia considerar como "histórico" o conceito de que "fenômenos do presente se desenvolveram a partir de formas prévias, das quais eles são geneticamente conectados" e de que até a evolução darwiniana era histórica, já que para White evolução não poderia jamais ser historia (!) (White, 1945, p.222).

$\mathrm{O}$ mesmo debate ocorreu, de maneira totalmente independente, paralela e duas décadas depois, entre um biólogo/paleontólogo e um geólogo/filósofo. Nesse caso tratava-se respectivamente de George Gaylord Simpson e Richard Watson.

Simpson (1963) defendeu a existência de ciências históricas, entre elas a biologia e a geologia, em contraposição às ciências físicas, como química e física. O raciocínio de Simpson se baseou na distinção entre propriedades imanentes, que seriam aquelas propriedades imutáveis da matéria e da energia, bem como os processos e princípios igualmente imutáveis delas resultantes, e propriedades contingentes ou configuracionais, que seriam aquelas em constante mudança, 
relacionadas ao estado do Universo ou de alguma parte dele em um dado intervalo de tempo. Nesse raciocínio, uma ciência histórica poderia ser definida como "a determinação de sequencias configuracionais, sua explanação e o teste de tais sequencias e explanações" (ibidem, p.25). No caso da geologia (descrita por Simpson como uma das ciências com maior diversidade interna), ela lidaria com propriedades imanentes e processos relacionados com a porção física da Terra, e tal aspecto seria basicamente a-histórico. Esse ramo da geologia poderia ser considerado como um ramo da física ou da química aplicado a um objeto de estudo chamado Terra. Quando as mudanças pelas quais a Terra passou começam a ser levadas em consideração, entramos no domínio das propriedades configuracionais. Os processos históricos não poderiam ser entendidos por meio de leis como as que operam na física e na química, e a predição de fenômenos nas ciências históricas seria bastante improvável, possível apenas na condição de que as causas imanentes fossem totalmente conhecidas e, ao mesmo tempo, as similaridades das circunstâncias configuracionais fossem não só conhecidas como recorrentes (ibidem, p.37).

Watson (1966) discordou totalmente de Simpson, argumentando que ele falhou ao distinguir dois tipos de eventos: aqueles que na verdade são abstrações e fazem parte de nosso arsenal conceitual, e aqueles que são instâncias do mundo real. Uma reação química enquanto conceito seria a-histórico. Uma reação química real seria um evento histórico, assim com uma experiência química feira por Lavoisier também seria. Cada molécula da substância A teria se combinado com a outra da substância B de maneira particular, apesar de o resultado final ser indistinguível entre reações ocorridas em tubos de ensaios diferentes. Segundo Watson (1966, p.176), nós só não prestamos atenção à maneira ou à sequencia em que ocorreram essas diferentes instâncias de reação química porque não temos interesse (e nem equipamentos de medição) para fazê-lo. Mostrando seu alinhamento com a corrente positivista de Hempel (ibidem, p.180), e em paralelo ao raciocínio de Leslie White, Watson afirmou que "toda explanação científica é uma generalização regida por leis" e que "tais leis são mais fáceis de serem definidas e mais uteis na Química do que na Geologia", mas não haveria razão para se pensar que existisse uma diferença lógica entre as duas ciências. Em suma, geologia seria igual a Química, ou mais explicitamente "Portanto, a geologia é uma ciência exata" (ibidem, p.179).

Em suma, Watson parte de uma postura ontológica distinta de Simpson, por negar veementemente a existência de indeterminações ou contingência. Em suas palavras, "a racionalidade depende da determinação. Se não existisse a possibilidade de determinação 'exata' em qualquer nível, não existiria ciência" (ibidem, p.184). Usando como exemplo a forma e a direção de um ravinamento ocorrendo em uma vertente, que podem ser considerados impossíveis de se predizer, Watson diz que eles poderiam ser previstos se "todas as medidas possíveis de declividade, tamanhos dos grãos, microdiferenças na litologia and so on" 
fossem feitas. Se em um plano filosófico seria possível medir todas as variáveis relacionadas a um fenômeno, na prática isso é impossível, seja pelo tempo envolvido, seja por que para serem medidas, essas variáveis têm que ser determinadas de antemão, e a determinação delas depende da teoria que as informa. Como a ciência (que é justamente o que Watson defende com tanta veemência) se relaciona a fenômenos, então o raciocínio de Watson, que é eminentemente filosófico nesse quesito, torna-se inócuo. Há uma diferença prática e fundamental entre ciências históricas e a-históricas, e como a ciência é uma questão prática, no sentido em que ela é empregada para entender o mundo físico e não questões filosóficas, essa diferença deve ser explicitamente apresentada. O não entendimento das diferenças entre ciências históricas e a-históricas leva a uma confusão cujo resultado é a recorrente dicotomia entre "ciência" $\mathrm{e}$ "humanidades". Um exemplo (dentre muitos) pode ser visto em Leach (1973, p.764) ao argumentar que a ciência pode levar o homem à Lua e predizer com precisão de segundos quando a nave vai cair no mar ao regressar, mas é incapaz de predizer a taxa de conversão entre o dólar e a libra esterlina, sendo essa a "diferença entre coisas governadas por leis naturais e coisas governadas por intenção bumana”. Ora, não só a taxa do dólar, mas também a extinção dos dinossauros estão nesse mesmo domínio. Além do mais, se a taxa do dólar fosse regida pela intenção humana, não haveria mercado especulativo. Como vimos na citação de Leach (1973), o arqueólogo deveria se ater à crônica, às perguntas do tipo "o que" aconteceu. As perguntas do tipo "como" ou "por que" algo aconteceu estariam fora de seu domínio. A explanação arqueológica seria impossível, posto que entraria no domínio da especulação. Apenas antropólogos poderiam alcançar esse elevado patamar. Como então pode ser desatado esse nó? Pela constatação de que a evolução tem um componente cronológico e um componente explanatório. Que para a aplicação de um modelo teórico (evolução) é necessário antes uma crônica ( $\mathrm{O}^{\prime}$ Hara, 1988). Que em uma ciência histórica, idiográfico e nomotético andam juntos, são interdependentes (Simpson. 1963, p.46).

Tendo em vista o exposto, podemos dizer que o que a ciência almeja, em termos gerais, é explanar e predizer. Como vimos, algumas ciências têm mais sucesso nos aspectos preditivos, outras nos aspectos explanatórios, mas de um modo geral essas duas características são importantes dentro do conceito de ciência. Quando falamos em predição estamos nos referindo a um relato ou uma narrativa sobre algo que não existe no momento presente, mas que pode ocorrer ou ter ocorrido em algum outro momento (Schumm, 1991, p.7). Temos que levar em consideração um sentido amplo da palavra, que envolve também a retrodição, ou seja, fornecer uma narrativa sobre algo que não ocorre no momento presente mas que pode ter ocorrido no passado (Gallay, 1986; Runciman, 2005). Nesse aspecto, a arqueologia pode ser considerada tanto como capaz de explanação como de predição. Além da questão da retrodição, não seria demasiado dizer que a arqueologia tem um potencial enorme de fornecer subsídios para 
a construção de cenários futuros, dentro de uma ideia de predição no sentido livre. Que a arqueologia não o faça com mais frequência tem mais a ver com limitações autoimpostas do que com qualquer característica inerente ao exercício da disciplina.

\section{O método científico em arqueologia}

É necessário reconhecer que há um forte componente hermenêutico no método científico arqueológico, característica compartilhada com as Ciências da Terra, conforme apresentado anteriormente. A hermenêutica (ou "teoria da interpretação") pode iluminar alguns pontos ainda obscuros no tocante a como funciona o método científico nas ciências históricas (Frodeman, 1995, 2003). A ideia do círculo hermenêutico, onde a compreensão do todo depende da compreensão das partes e vice-versa, é instrumental no entendimento de como funciona a arqueologia. Esse círculo pode ser considerado como vicioso em termos lógicos, porque poderia implicar um raciocínio circular, mas na realidade pode ser mais bem compreendido como uma espiral. Ao entrarmos no círculo, podemos fazê-lo por dois lados: pouco sabendo do todo mas interessados no particular, ou ao contrário, pouco sabendo das particularidades mais interessados no geral. O fato é que a correta compreensão do "texto" depende da integração do geral e do particular. Como a hermenêutica foi desenvolvida para tratar de textos literários ou religiosos, toda a aplicação do raciocínio em arqueologia é, obviamente, analógica. O "texto" que queremos interpretar em arqueologia não foi escrito por ninguém, ou melhor, não foi escrito de maneira intencional, mas ainda assim é resultado de um encadeamento de fatos operados por agentes vários e tão díspares como seres humanos, rios, fenômenos atmosféricos, plantas e reações químicas. Sendo assim, esse registro é passível de uma leitura histórica. A pedra lascada, a cerâmica, o pólen e os sedimentos; os fragmentos de carvão, os fitólitos, o colúvio que recobriu tudo; os fundos de lago, as vertentes e os terraços de rio. Tudo isso gera um texto, ou vários textos, que podem ser lidos. A chave da leitura desses textos é dada por diferentes disciplinas. Assim como para os filósofos há uma interpretação mais correta de um determinado texto, por meio da chamada "compreensão", que une os horizontes do leitor e do autor (Schmidt, 2014) há, para os arqueólogos, a igual compreensão do (con)texto arqueológico por meio da junção dos horizontes do pesquisador (seu conhecimento prévio, ou seus preconceitos) com os vestígios do que ocorreu no passado. A entrada no círculo hermenêutico se dá pelo treinamento formal; aprende-se a ler uma lasca, um fragmento cerâmico ou um perfil de solo. Uma vez que essa chave é dada, não há mais volta. Um afloramento na beira da estrada nunca mais será apenas um mero barranco, uma lasca nunca mais será apenas um pedaço de pedra quebrada. A leitura do contexto arqueológico se dará por meio de idas e vindas, as interpretações sendo checadas e reformuladas em confrontação com novos dados, e a volta ao redor do círculo nunca mais passa pelo mesmo ponto. Entra-se em uma espiral interpretativa que leva, eventualmente, 
a uma interpretação mais próxima da realidade. Para isso, a interdisciplinaridade é fundamental.

Conforme visto anteriormente, o método científico nas ciências históricas é necessariamente distinto do método experimental/laboratorial que costuma ser associado às ciências a-históricas. No caso específico da arqueologia, o método científico acaba por ser muito semelhante ao que os colegas das Ciências da Terra executam. Em primeiro lugar, o teste de hipóteses em Arqueologia não se dá, de maneira alguma, como queriam os proponentes do Processualismo. Ao contrário do que propunham Binford (1968) e Fritz e Plog (1970), testar uma hipótese em arqueologia não se trata de uma argumentação estritamente lógica, seguindo o modelo de Hempel. Trata-se de algo muito mais sutil, e que foi apresentado de maneira apropriada no final do século XIX por Thomas Chamberlin (1897), e denominado "método das múltiplas hipóteses de trabalho". O texto de Chamberlin, um clássico nas Ciências da Terra mas pouco conhecido por arqueólogos, fornece uma visão bastante realista do método em uma disciplina que depende de observações em campo e de um diálogo entre teoria e empirismo. Inicialmente, Chamberlin argumenta que o desenvolvimento dos métodos científicos segue três etapas históricas: 1 ) teoria dominante; 2 ) hipótese de trabalho e 3 ) múltiplas hipóteses de trabalho.

Em um primeiro momento, durante o estabelecimento de uma disciplina, é desenvolvida uma ideia para explicar uma categoria de fenômenos, e rapidamente essa ideia é alçada à categoria de teoria dominante ("ruling theory" no original). Segundo Chamberlin, o pesquisador desenvolve uma relação afetiva com sua teoria, e começa a tratá-la como um filho. Seus seguidores o imitam. Em seguida, como contraponto aos problemas trazidos por essa abordagem, há um movimento no sentido contrário, de relegar a teoria a um segundo plano e trazer as observações empíricas para a linha de frente, ou seja, há uma desvalorização da teoria e uma valorização do empirismo, na forma do método da hipótese de trabalho. Nesse caso, o método é eminentemente indutivo. O antídoto seria a multiplicidade de "filhos", ou seja, o método das múltiplas hipóteses de trabatho. O pesquisador se esforçaria para pensar em várias maneiras possíveis de se explicar um dado fenômeno, dando origem, assim, a vários "filhos intelectuais", incluindo a adoção de "filhos" de outrem. No processo de confrontação com a realidade, vários desses “filhos” perecerão, mas outros sobreviverão, e é possível que mais de um sobreviva, tendo em vista que um mesmo fenômeno pode ter múltiplas causas e diferentes ideias podem ser combinadas em um sistema explanatório coerente. $\mathrm{O}$ método das múltiplas hipóteses evita, assim, a rigidez de pensamento e o dogmatismo. Enfim, a linguagem colorida de Chamberlin e sua lucidez fazem do texto um clássico extremamente atual.

Em arqueologia, o método de múltiplas hipóteses de trabalho é provavelmente utilizado pela maior parte dos praticantes, mesmo que de maneira implícita. A multiplicidade de interpretações possíveis acaba por ter que se relacionar 
com a realidade empírica, e isso ocorre de maneira independente da postura teórica do pesquisador. Nas palavras de Hodder (1999, p.200):

Todos nós interpretamos o passado a partir de diferentes perspectivas e essas diferentes interpretações podem ser avaliadas em relação à evidência [...] a evidência arqueológica tem uma materialidade "objetiva" que limita e confronta o que pode ser dito sobre ela [...].

Em suma, o método de múltiplas hipóteses de trabalho é operacionalizado por meio de "triangulação" ou da convergência de múltiplas linhas de evidência extraídas do universo empírico, e que apontam para alguma ou algumas das hipóteses propostas, mas não para outras. A utilização de diferentes métodos advindos de diferentes áreas do conhecimento é imprescindível nessa empreitada. Obviamente consideramos como hipóteses viáveis apenas aquelas ideias que têm alguma implicação ou colagem com o universo empírico. Ideias sem essa característica estão fora do domínio do método científico, e efetivamente entram no âmbito do que Leach (1973) chamou de "pura especulação".

\section{A arqueologia como exemplo de ciência interdisciplinar}

Não existe, atualmente, disciplina acadêmica mais interdisciplinar do que a Arqueologia. Além do aporte vindo das Humanidades, a Arqueologia é totalmente dependente das Ciências da Terra, da Biologia, da Física e da Química. Além disso, o montante titânico de dados produzidos por uma única etapa de escavação só pode ser analisado por meio de métodos estatísticos. A interdisciplinaridade é imprescindível no exercício da arqueologia, simplesmente porque não existe arqueologia “pura”. A definição mais básica de arqueologia, como sendo o estudo de artefatos operacionalizado por meio do conceito de cultura, já coloca dois campos acadêmicos distintos em contato: o mundo material, geralmente objeto de estudo das "bard sciences", com o mundo das ideias, mais próximo das Humanidades. Porém, não podemos nos esquecer de que o organismo responsável pela elaboração desses artefatos é um ser vivo, e seu entendimento tem que passar também por uma abordagem biológica. Não bastasse isso, os artefatos produzidos por esse ser, que é ao mesmo tempo cultural e biológico, estão, na maior parte das vezes, imersos em uma matriz sedimentar, objeto das Ciências da Terra. Por fim, coroando toda essa diversidade, a abordagem teórica utilizada na explanação desses fenômenos culturais tem que dar conta de mudanças que ocorrem ao longo do tempo e do espaço, dentro de uma ontologia materialista e evolutiva, que separa claramente a Arqueologia de suas disciplinas irmãs. Em suma, a arqueologia é a rainha da interdisciplinaridade. Essa constatação, porém, pode ser vista de diferentes ângulos. Há os que prezam essa característica interdisciplinar e independente da arqueologia, assim como há os que parecem se sentir desamparados ao perceberem que sua atividade acadêmica não está necessariamente amarrada a nenhum porto, e não cabe dentro de nenhum hangar. Suspeito que desse desconforto nasçam os motes do gênero "Arqueologia é [.... insira neste espaço a disciplina que mais lhe agrada] ou não é nada". 
No entanto, esse desconforto não é infundado. Sendo o mundo acadêmico uma agremiação de pessoas, nada mais humano do que querer fazer parte de algum grupo, e o preço que se paga por transitar em diferentes "gêneros acadêmicos" é relativamente alto. Há também uma questão de legitimidade socioacadêmica, uma vez que ser considerado como integrante de uma disciplina estabelecida é sempre melhor, especialmente se os integrantes dessa outra disciplina são maioria no departamento. Por fim, há também os que, por falta de conhecimento, preferem ficar em sua zona de conforto e emitir opiniões do tipo "mas, se você quer trabalhar com fauna, por que não vai para um departamento de Biologia?".

Enquanto disciplina científica, a estrutura da Arqueologia é muito semelhante à da Biologia, da Geologia e da Geografia (em especial a Geografia Física - ou as chamadas Ciências da Terra), fato esse já observado por vários autores (e.g., Cochrane, 2009, p.114-16; Gallay, 1986, p.100-3; Lyman; O’Brien, 1998; Renfrew, 1983; Schummm 1991, p.3; Watson et al., 1984, p.45). Do ponto de vista estrutural ou epistemológico, as quatro disciplinas não possuem uma maneira única de abordar seu objeto de estudo. Podemos dizer que facetas distintas da realidade são abordadas de maneiras diferentes, utilizando-se de corpos teóricos distintos porém integrados (Araujo, 1999). Isso pode parecer um truísmo, porque qualquer disciplina acadêmica vai acabar abordando facetas distintas da realidade de maneira diferente, mas o que queremos dizer aqui é que, apesar de ser possível abordar diferentes aspectos de uma sociedade de maneiras distintas, ou de analisar documentos históricos abordando-os a partir de maneiras distintas, não existe nas Humanidades uma diferença explícita e estrutural que diferencie essas abordagens. O uso de uma abordagem, por exemplo, da Escola dos Annales (e.g., Braudel, 1958), em que se postula que a História pode ser mais bem entendida por meio de uma abordagem em diferentes níveis, é uma escolha pessoal do pesquisador. Ele pode ou não seguir a Escola dos Annales, mas a História enquanto disciplina não é estruturada necessariamente dessa forma. O mesmo vale para as diferentes escolas da antropologia e da sociologia. Essas diferentes abordagens são manifestações do interesse e da formação do pesquisador, e não têm um papel necessário na estrutura da disciplina. Por isso, é importante notar que a estrutura da arqueologia difere fundamentalmente da estrutura das Humanidades em geral, e isso se observa de duas maneiras: a arqueologia, assim como a biologia evolutiva e a geologia histórica, possui um componente de cunho idiográfico, onde a contingência histórica reina, mas ao mesmo tempo são perceptíveis processos regulares que estão presentes, como plano de fundo, no desenrolar desses eventos. A arqueologia é uma ciência histórica e, portanto, não almeja o estabelecimento de "leis". Do mesmo modo, não há "leis" na biologia (Mayr, 1996; Scriven, 1959). Seres vivos estão sujeitos a toda sorte de interferências da contingência histórica e do acaso, e são todos únicos. Mesmo organismos geneticamente idênticos não são fenotipicamente idênticos e, portanto, interagem com o mundo de maneiras distintas. Há, po- 
rém, um processo nos bastidores que nunca cessa, que chamamos de evolução. Quanto à existência de "leis" na geologia, apesar do nome, as famosas "Leis da Estratigrafia" de Nicolaus Steno (1638-1686) são instâncias particulares da Lei da Gravidade, essa sim uma lei no sentido estrito. Se realmente se tratam de "leis", há controvérsias, e depende do sentido que se dá à palavra "lei" (e.g., Mayr, 1961; Simpson, 1963, contra Watson, 1966, 1976). A semântica sugere algo que deve ser obedecido, e nesse sentido creio que, seguindo Mayr, não existem leis nem na Biologia e nem nas Ciências da Terra (cf. Schumm, 1991; a menos que estejamos falando das sub-áreas dessas disciplinas que lidam com reações químicas, como seria o caso da biologia molecular, da fisiologia ou da cristalografia). Um problema adicional é o fato de que na arqueologia esse termo é tão carregado de conotações negativas que é melhor simplesmente não usá-lo.

Ainda em termos de estrutura, temos nessas disciplinas uma dependência total de outras áreas de conhecimento, e por isso elas são chamadas ciências derivadas (Schumm, 1991, p.3), aquelas que necessariamente se utilizam de conceitos e informações de outras disciplinas, algo que não costuma ocorrer nas Humanidades. Conquanto possa haver interesses interdisciplinares, a História, a Antropologia e a Sociologia, por exemplo, não dependem necessariamente da Geomorfologia, da Geologia ou da Biologia para funcionarem, e muito menos da Química ou da Física. Quando, no âmbito das Humanidades, alega-se que algo é interdisciplinar, isso geralmente ocorre entre as próprias Humanidades, quando não dentro da mesma disciplina (por exemplo, quando se propõe uma abordagem "interdisciplinar" entre História Econômica e Demografia Histórica).

Em suma, se há vários motivos para supor-se que a arqueologia deva ser parte de alguma outra disciplina, nenhum deles passa pela ontologia, epistemologia ou pela simples prática científica, e sim por questões de política acadêmica ou pendor pessoal. A arqueologia, com essa característica um tanto anárquica, onde diferentes disciplinas são empregadas e nenhuma delas consegue se impor sobre as outras, acaba por se constituir em um paradigma de ciência que consegue congregar várias ontologias em um só ramo do conhecimento. Paradoxalmente, a disciplina que está mais voltada para o passado é justamente a que melhor prenuncia como será a ciência no futuro.

Agradecimentos - Este trabalho não teria sido possível sem o apoio do Instituto de Estudos Avançados da Universidade de São Paulo, por meio do Programa Ano Sabático. Gostaria de agradecer especialmente a Martin Grossmann e Paulo Saldiva pelo apoio durante esse período academicamente tão rico. Agradeço também aos meus colegas do Programa Sabático do IEA pela agradável e intelectualmente instigante convivência: Rodolfo Coelho de Souza, Mary Gasalla, Dária Jaremtchuk, Lúcia Barbosa de Oliveira e Flavio Ulhoa Coelho. Agradeço também ao parecerista anônimo que teceu comentários bastante pertinentes ao texto, melhorando sua qualidade. 


\section{Referências}

ARAUJO, A. G. M. As geociências e suas implicações em teoria e métodos arqueológicos. Revista do Museu de Arqueologia e Etnologia, Anais da I Reunião Internacional de Teoria Arqueológica na America do Sul. Sup.3, p.35-45, 1999.

BABICH, B.; GINEV, D. (Ed.) The multidimensionality of hermeneutic phenomenology. Cham: Springer, 2014.

BAMFORTH, D. B.; SPAULDING, A. C. Human behavior, explanation, archaeology, history, and science. Journal of Anthropological Archaeology, v.1, p.179-95, 1982.

BAYARD, D. T. Science, theory, and reality in the "New Archaeology". American Antiquity, v.34, p.376-84, 1969.

BINFORD, L. R. Archaeology as anthropology. American Antiquity, v.28, p.217-25, 1962.

Some comments on historical versus processual archaeology. Southwestern Journal of Anthropology, v.24, p.267-75, 1968.

BOAS, F. The history of anthropology. Science, New Series, v.20, p.513-24, 1904.

BRAUDEL, F. Histoire et sciences sociales: La longue durée. Annales. Économies, Sociétés, Civilisations, v.4, p.725-53, 1958.

BUNGE, M. Philosophy of science - From problem to theory. New Brunswick: Transaction Publishing, 1998. v.I.

CHAMBERLIN, T. C. The method of multiple working hypothesis. Journal of Geology, v.5, p.837-48, 1897.

CLARKE, D. L. Analytical Archaeology. London: Methuen, 1968.

Review: Patty Jo Watson, Steven A. LeBlanc and Charles L. Redman: Explanation in Archaeology: An Explicitly Scientific Approach. New York and London: Columbia University Press, 1971. 191p., 8 figs.£ 3.30. Antiquity, v.46, p.237-9, 1972.

Archaeology: the loss of innocence. Antiquity, v.46, p.6-18, 1973.

CLELAND, C. E. Historical science, experimental science, and the scientific method. Geology, v.29, p.987-990, 2001.

. Methodological and epistemic differences between historical science and empirical science. Philosophy of Science, v.69, p.474-96, 2002.

COCHRANE, E. E. Evolutionary explanation and the record of interest. In: SHENNAN, S. Pattern and process in cultural evolution. Berkeley: University of California Press, 2009. p.113-32.

CREASE, R. P. Hermeneutics and the natural sciences: Introduction. Man and World, v.30, p.259-70, 1997.

DE QUEIROZ, K. Species concepts and species delimitation. Systematic Biology, v.56, p.879-86, 2007.

DESCOLA, P. On anthropological knowledge. Social Anthropology, v.13, p.65-73, 2005.

DILTHEY, W. Selected works, volume I: Introduction to the Human Sciences. In: R. A. Makkreel; F. Rodi ed. Princeton: Princeton University Press, 1989. 
DUNNELL, R. C. Science, social science, and common sense: The agonizing dilemma of modern archaeology. Journal of Anthropological Research, v.38, p.1-25, 1982.

Methodological issues in contemporary Americanist archaeology. Proceedings of the Biennial Meeting of the Philosophy of Science Association 1984, v.2, p.717-44, 1984.

Is a scientific archaeology possible? In: EMBREE, L. Metaarchaeology. Dordrecht: Springer Netherlands, 1992. p.75-97.

DUTRA, L. A. Introdução à teoria da ciência. Florianópolis: Editora da Universidade Federal de Santa Catarina, 2009.

EGER, M. Achievements of the hermeneutic-phenomenological approach to natural science. Man and World, v.30, p.343-67, 1997.

EMBREE, L. The future and past of metaarchaeology. In: Metaarchaeology. Dordrecht: Springer Netherlands, 1992. p.3-50.

FABIAN, E. P. Karl Popper e o darwinismo. São Paulo: Habilis, 2009.

FEYERABEND, P. Adeus à razão. São Paulo: Editora Unesp, 2009.

FRITZ, J. M.; PLOG, F. T. The nature of archaeological explanation. American Antiquity, v.35, p.405-12, 1970.

FRODEMAN, R. Geological reasoning: Geology as an interpretive and historical science. Geological Society of America Bulletin, v.107, n.8, p.960-8, 1995.

. Geo-Logic: Breaking ground between philosophy and the earth sciences. Albany: State University of New York Press, 2003.

GALLAY, A. L'Archéologie démain. Paris: Belfond, 1986.

GHINS, M. Uma introdução à metafísica da natureza: representação, realismo e leis científicas. Curitiba: Editora da Universidade Federal do Paraná, 2013.

GIBBON, G. Anthropological archaeology. New York: Columbia University Press, 1984. Explanation in archaeology. Oxford: Basil Blackwell, Oxford, 1989.

GILBERT, G. K. The inculcation of scientific method by example, with an illustration drawn from the Quaternary geology of Utah. American Journal of Science, v.184, p.284-99, 1886.

GODFREY-SMITH, P. Theory and reality - an introduction to the philosophy of science. Chicago: The University of Chicago Press, 2003.

GUMERMAN, G. J.; PHILLIPS JUNIOR, D.A. Archaeology beyond anthropology. American Antiquity, v.43, p.184-91, 1978.

HAWKES, C. F. C. Archaeology as science: purposes and pitfalls. British Association, Presidential Address Section H, p.92-102, 1957.

HEELAN, P. A. Why a hermeneutical philosophy of the natural sciences? Man and World, v.30, p.271-98, 1997.

. The scope of hermeneutics in the natural science. Studies in the History and Philosophy of Science, v.29, p.273-98, 1998.

HODDER, I. The archaeological process: an introduction. Oxford: Blackwell, 1999.

HOWORTH, H. H. Proceedings at meetings of the Royal Archaeological Institute, 
June $3^{\text {rd }}$ 1908. Archaeological Journal of the Royal Archaeological Institute of Wiltshire, v.65, n.1, 1908.

HULL, D. L. Central subjects and historical narratives. History and Theory, v.14,n.3, p.253-74, 1975. 1999.

. The use and abuse of Sir Karl Popper. Biology and Philosophy, v.14, p.481-504,

JOHNSON JUNIOR, L. Problems in "avant-garde" archaeology. American Anthropologist, v.74, p.366-77, 1972.

JUDD, N. M. The present status of archaeology in the United States. American Anthropologist, v.31, n.3, p.401-18, 1929.

KLEJN, L. S. Metaarchaeology. Acta Archaeologica, v.72, n.1, p.1-149, 2001.

KOHL, P. L. Limits to a post-processual archaeology (or, The dangers of a new scholasticism). In: YOFFEE, N.; SHERRATT, A. Archaeological Theory: Who Sets the Agenda? Cambridge: Cambridge University Press, 1997. p.3-19.

KROEBER, A. L. Historical reconstruction of culture growths and organic evolution. American Anthropologist, v.33, p.149-56, 1931.

. History and science in anthropology. American Anthropologist, v.37, n.4, p.539-69, 1935.

. An anthropologist looks at history. Pacific Historical Review, v.26, p.281-7, 1957.

KUHN, T. S. The structure of scientific revolutions. International Encyclopedia of Unified Science II. 2.ed. Chicago: University of Chicago Press, 1970.

KUPER, A. Culture - the anthropologists' account. Cambridge: Harvard University Press, 1999.

LEACH, E. Concluding Address. In: RENFREW, C. The explanation of culture change: models in prehistory. London: Duckworth, 1973. p.761-71.

LEWIS, D. Counterfactual dependence and time's arrow. Nồs, v.13, p.455-76, 1979.

LEWONTIN, R. C. Testing the theory of natural selection. Nature, v.236, n.5343, p.181-2, 1972 .

LYMAN, R. L.; O’BRIEN, M. J. The goals of evolutionary archaeology: History and explanation. Current Anthropology, v.39, p.615-52, 1998.

LYOTARD, J.-F. The postmordern condition: a report on knowledge. Manchester: Manchester University Press, 1984.

MAHNER, M.; BUNGE, M. Foundations of biophilosophy. Berlin: Springer, Berlin, 1997.

MANTZAVINOS, C. Naturalistic hermeneutics. Cambridge: Cambridge University Press, 2005.

MAYR, E. Cause and effect in biology. Science, v.134, n.3489, p.1501-6, 1961.

1972.

. The nature of the Darwinian revolution. Science, v. 176, n.4038, p.981-9,

The growth of biological thought: diversity, evolution, and inheritance. Cam-

bridge: Harvard University Press, 1982. 
MAYR, E. The autonomy of Biology: The position of Biology among the sciences. The Quarterly Review of Biology, v.71, p.97-106, 1996.

. What Evolution Is. London: Phoenix, 2002.

. What makes biology unique? Considerations on the autonomy of a scientific discipline. Cambridge: Cambridge University Press, 2004.

MERCINIER, E. Congrès International d'Anthropologie et d'Archéologie Préhistoriques. Compte rendu de la XIVe session. Genève 1912. Publié par les soins de M. Waldemar Deonna. 1913. Le Globe. Revue Genevoise de Géographie, v.53, n.1, p.68-9, 1914. MOIR, J. R. The position of prehistoric research in England. Proceedings of the Prehistoric Society of East Anglia, v.2, n.3, p.381-91, 1917.

O'HARA, R. J. Homage to Clio, or, toward an historical philosophy for evolutionary biology. Systematic Zoology, v.37, p.142-55, 1988.

O'MEARA, J. T. Anthropology as empirical science. American Anthropologist, v.91, p.354-69, 1989.

PEACE, W. J. Leslie White and evolutionary theory. Dialectical Anthropology, v.18, p.123-51, 1993.

PEREIRA, O. O que é teoria. 7.ed. São Paulo: Brasiliense, 1990.

POPPER, K. Darwinism as a metaphysical research program. In: SCHILP, P. A. The Philosophy of Karl Popper. La Salle: Open Court, La Salle, 1974. p.133-43.

RENFREW, C. Geography, archaeology and environment. The Geographical Journal, v.149, p.316-33, 1983.

ROSSI, P. Os sinais do tempo - história da terra e história das nações de Hooke a Vico. São Paulo, Companhia das Letras, 1992.

RUNCIMAN, W. G. Culture does evolve. History and Theory, v.44, p.1-13, 2005.

RUSE, M. Karls Popper's philosophy of biology. Philosophy of Science, v.44, p.638-61, 1977.

SCHMIDT, L. K. Hermenêutica. Petrópolis: Vozes, 2004.

SCHUMM, S. A. To interpret the earth: ten ways to be wrong. Cambridge: Cambridge University Press, 1991.

SCRIVEN, M. Explanation and prediction in evolutionary theory. Science, v.130, n.3374, p.477-82, 1959.

SHANKS, M.; TILLEY, C. Social theory and archaeology. Albuquerque: University of New Mexico Press, 1987.

SIMPSON, G. G. Historical Science. In: ALBRITTON, C. C. The Fabric of Geology. Stanford: Freeman Cooper, 1963. p.24-48.

SOBER, E. Evolution, population thinking, and essencialism. Philosophy of Science, v.47, p.350-83, 1980.

STELLO, D. et al. Oscillating red giants observed during campaign 1 of the Kepler k2 mission: new prospects for galactic archaeology. The Astrophysical Journal Letters, 809: L3, 2015.

STERELNY, K. Philosophy of evolutionary though. In: RUSE, M.; TRAVIS, J. Evolution: the first four billion years. Cambridge: Harvard University Press, 2009. p.313-29. 
TILLEY, C. Interpreting material culture. In: PEARCE, S. M. Interpreting objects and collections. New York: Routledge, 1994. p.67-75.

TRIGGER, B. G. "The loss of innocence" in historical perspective. Antiquity, v.72, n.277, p.694-8, 1998.

WASSERMAN, G. On the nature of the theory of evolution. Philosophy of Science, v. 48, p.416-37, 1981.

WATSON, R. A. Geology is different: A critical discussion of "The Fabric of Geology". Philosophy of Science, v.33, p.172-85, 1966.

Laws, systems, certainty, and particularities. American Anthropologist, v.78, p.341-4, 1976.

WATSON, P. J.; LEBLANC, S. A.; REDMAN, C. L. Archaeological explanation: the scientific method in archaeology. New York: Columbia University Press, 1984.

WHITE, L. A. History, evolutionism, and functionalism: Three types of interpretation of culture. Southwestern Journal of Anthropology, v.1, p.221-48, 1945.

Kroeber's “Configurations of Culture Growth”. American Anthropologist, v.48, p.78-93, 1946.

WILLER, D.; WILLER, J. Systematic empiricism: critique of a pseudoscience. New Jersey: Prentice-Hall, 1973.

WYLIE, A. Thinking from Things: Essays in the Philosophy of Archaeology. Berkeley: University of California Press, 2002.

RESUMO - Neste artigo a arqueologia será utilizada como um estudo de caso ilustrando a discussão a respeito das diferentes modalidades de ciência e das diferentes ontologias envolvidas. Argumentamos que a arqueologia é tão interdisciplinar que não pode ser encarada da mesma maneira que outras disciplinas das Humanidades, tendo suas componentes ontológicas, epistemológicas, teóricas e práticas mais associadas às Ciências da Terra e à Biologia do que à História ou à Antropologia. Por fim, apresentamos a estrutura do método científico na arqueologia e como as suas características apontam para um modelo de interdisciplinaridade extrema, com poucos paralelos nas outras ciências. PALAVRAS-CHAVE: Arqueologia, Ciência, Interdisciplinaridade, Ciências históricas.

ABSTRACT - In this article Archeology will be used as a case study illustrating the discussion abouIn this article, Archeology will be used as a case study to illustrate the discussion about the different modes of Science and the different ontologies involved. We argue that Archeology is so interdisciplinary that it cannot be viewed in the same way as other disciplines of the Humanities, having its ontological, epistemological, theoretical and practical components more associated with Earth Sciences and Biology than with History or Anthropology. Finally, we present the structure of the scientific method in Archeology and how its characteristics point to a model of extreme interdisciplinarity, with few parallels in the other sciences.

KEYWORDS: Archaeology, Science, Interdisciplinarity, Historical sciences. 
Astolfo Gomes de Mello Aranjo é professor do Museu de Arqueologia e Etnologia da Universidade de São Paulo (MAE-USP). Participou do Programa Ano Sabático do Instituto de Estudos Avançados da USP em 2016. @ - astwolfo@usp.br

Recebido em 18.9.2017 e aceito em 24.4.2018.

${ }^{\mathrm{I}}$ Museu de Arqueologia e Etnologia, Universidade de São Paulo, São Paulo, São Paulo Brasil. 